\title{
Cancer Antigen 27-29 Measurement
}

National Cancer Institute

\section{Source}

National Cancer Institute. Cancer Antigen 27-29 Measurement. NCI Thesaurus. Code C111143.

The determination of the amount of cancer antigen 27-29 present in a sample. 